\title{
The effects of mannan oligosaccharide and Streptococcus faecium addition to milk replacer on calf performance
}

S J Morrison, A F Carson, D J Kilpatrick

Agri-Food and Biosciences Institute, Hillsborough, United Kingdom

\author{
Email: steven.morrison@afbini.gov.uk
}

Introduction Calf diarrhoea is a significant health issue in dairy rearing enterprises, with $38 \%$ of producers reporting it to be a problem (Morrison et al., 2009). Non-antibiotic administration techniques commonly used to help prevent the invasion and growth of these pathogenic bacteria include that of offering competitive bacteria (probiotics) or substances in the milk replacer that prevent the pathogenic bacteria from adhering to the gut wall and therefore prevent scours from occurring (e.g. mannan oligosaccharides (MOS)). Previous research reported positive effects of probiotics on calf health, but there are no published data in the literature on the effect of probiotics on calf health and performance in a group feeding situation using computer controlled feeders. Group housing and feeding of calves increases the risk of disease transmission but is becoming a more common rearing practice. This necessitates investigation of management and nutritional factors that affect calf health and performance in group housed environments. The addition of probiotics or MOS has been shown to have a positive impact on starter intake and with starter intake being a key indicator to signal when to commence weaning (Morrison et al., 2009), inclusion in the calf's diet, through promotion of starter intake, could potentially reduce the age at weaning. The objectives of the current study were to examine the effect of offering calves milk replacer containing either MOS, probiotic (Streptococcus faecium) or a combination of both (MOS+PRO) on the growth and health of dairy calves in a group situation fed using computer controlled milk and concentrate feeders.

Material and methods Thirty-one Holstein-Friesian, 3 Norwegian Red and 46 Holstein-Friesian crossbred calves were assigned to 1 of 4 dietary treatments based on zinc sulphide turbidity score (ZST), birth weight, gender and genotype at 4 days of age. Calves were born between 31 January and 23 April. Treatments included: 600 g/calf/day of a $23 \%$ crude protein milk replacer with no supplement added (C); $\mathrm{C}$ with the addition of $10 \mathrm{~g} / \mathrm{MOS} /$ calf/day; C with probiotic (Streptococcus faecium EEC Reg. no. EI705 - 5x109 CFU/g) included in the milk replacer (PRO); and C with both MOS and PRO included (MOS+PRO). Calves were fed individually, within a group pen, using computerised milk and concentrate dispensers. Milk replacer was offered at a rate of $600 \mathrm{~g} / \mathrm{d}$ until concentrate intake averaged $500 \mathrm{~g} / \mathrm{d}$ for 4-days at which stage the computer-controlled programme automatically reduced milk replacer intake. When calves consumed an average of $1.5 \mathrm{~kg} / \mathrm{d}$ of concentrate over a 4-d period, milk replacer feeding was finished. Calf health, feed intakes and performance was recorded until 10 weeks. Due to unequal replication for the various treatments, continuous data were analysed using the Genstat REML procedure for the analysis of variance of unbalanced data. This fitted a fixed model with effects for gender, genotype, birth weight, ZST score and treatment. Health data were analysed by binomial and Poisson regression with birth weight, ZST score, gender and treatment included in the model. Pairwise t-tests were used to test for treatment differences.

Results Milk replacer intake for each treatment is presented in Table 1. Daily concentrate intake during week 4 was greater $(\mathrm{P}<0.05)$ with calves offered MOS or PRO compared with calves offered $\mathrm{C}$ (Figure 1). However, weaning age was not significantly affected by supplementation with MOS or PRO. Faecal score was significantly lower with calves offered supplements, although no difference in the number of scour episodes was detected. The inclusion of supplements had no significant effect on calf growth compared with calves offered the $\mathrm{C}$ treatment (Table. 1).

Table 1 Treatment effects on intake and performance of calves

\begin{tabular}{lllllll}
\hline & C & MOS & PRO & MOS+PRO & SED & P-value \\
\hline Number of calves & 19 & 19 & 21 & 21 & & \\
Milk replacer (kg DM) & 25.6 & 23.3 & 25.4 & 26.5 & 1.12 & 0.07 \\
Concentrate (kg DM) & 17.7 & 17.4 & 18.6 & 17.5 & 1.56 & 0.83 \\
Weaning age (day) & 52 & 49 & 50 & 52 & 2.06 & 0.47 \\
Mean faecal score & $1.16^{\mathrm{b}}$ & $1.11^{\mathrm{a}}$ & $1.11^{\mathrm{a}}$ & $1.09^{\mathrm{a}}$ & 0.02 & 0.03 \\
No. of scour episodes & 0.31 & 0.28 & 0.37 & 0.17 & 0.15 & 0.94 \\
Live weight (kg) & 56.0 & 55.3 & 57.2 & 54.9 & 1.1 & 0.71
\end{tabular}

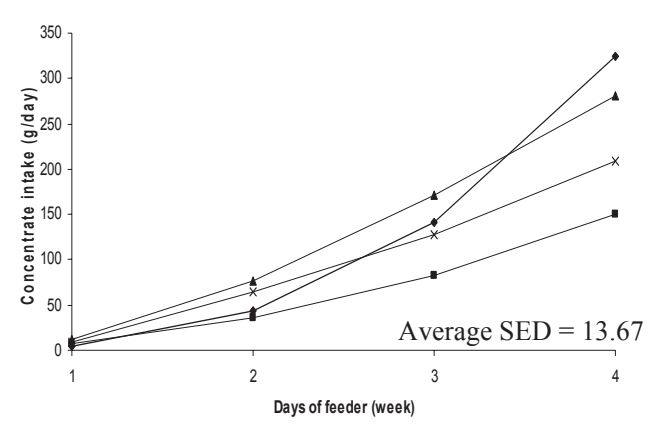

Figure 1. Weekly concentrate intake until week 4 of calves offered no supplement $(\mathbf{v})$, MOS $(\downarrow)$, PRO $(\mathbf{\Delta})$ or MOS+PRO $(x)$

${ }^{\#} 1=$ normal consistency; $2=$ slightly liquid; $3=$ moderately liquid and 4=primarily liquid

a , b values with different superscript are significant different $(\mathrm{P}<0.05)$

Conclusions Calves offered MOS or PRO, despite having increased concentrate intake at an earlier age, had a similar live weight and body size compared with unsupplemented calves throughout the study. MOS, PRO and MOS + PRO addition to dairy calf diets reduced the faecal score of calves compared with unsupplemented calves, although no reduction in the incidence in scour was observed.

\section{References}

Morrison, S. J., Carson, A. F., Matthews D. and Mulholland, M. 2009. Proceedings of British Society of Animal Science Annual meeting, 84 